Original Research Article

\title{
Patient-reported outcomes with medical management of benign prostatic hyperplasia: a prospective study in a tertiary care teaching hospital of rural West Bengal, India
}

\author{
Soumitra Mandal', Ananya Mandal ${ }^{2 *}$, Tapas K. Majhi ${ }^{3}$, Sonai Mandal' \\ Tanmoy Gangopadhyay ${ }^{2}$, Asoke K. Das ${ }^{2}$
}

\begin{abstract}
${ }^{1}$ Department of Pharmacology, All India Institute of Medical Sciences, Rishikesh,

Uttarakhand, India

${ }^{2}$ Department of Pharmacology, Bankura Sammilani Medical College, Bankura, West Bengal, India

${ }^{3}$ Department of Urosurgery, Nilratan Sircar Medical College, Kolkata, West Bengal, India
\end{abstract}

Received: 03 February 2017

Revised: 16 May 2017

Accepted: 19 May 2017

*Correspondence to:

Dr. Ananya Mandal,

Email: drananyamandal@ gmail.com

Copyright: (C) the author(s), publisher and licensee Medip Academy. This is an openaccess article distributed under the terms of the Creative Commons Attribution NonCommercial License, which permits unrestricted noncommercial use, distribution, and reproduction in any medium, provided the original work is properly cited.

\begin{abstract}
Background: Effectiveness of pharmacotherapy in benign prostatic hyperplasia $(\mathrm{BPH})$ is generally evaluated by clinical measures. Outcome of the treatment from the patient's perspective however cannot be evaluated which may result communication gap between the patient and the physician. Patient-Reported Outcomes (PRO) studies can bridge this gap. This study was undertaken to evaluate outcomes and to assess the impact of medical management of BPH on general health-related quality of life.

Methods: In this prospective, observational study, eligible patients with BPH attending a Urology clinic in a tertiary care rural hospital of West Bengal were enrolled and followed up on third and sixth months from baseline. Symptom assessment of BPH were assessed through International Prostate Symptom Score (I-PSS), BPH Impact Index (BII) and Health Related Quality of life questionnaires. Tools of descriptive statistics were used for analysis of data.

Results: In the study population of 66 patients, 50\% were treated with monotherapy (alpha blockers) and 50\% were treated with combinations (alpha blocker and 5alpha reductase inhibitors). After 6 months of medical management, I-PSS was decreased from $18.86 \pm 5.53$ to $11.76 \pm 3.94$ (p <0.001), BII score decreased from $9.65 \pm 2.59$ to $5.89 \pm 2.24(\mathrm{p}<0.001)$ and VAS score increased from $51.44 \pm 10.03$ to $54.24 \pm 11.38$ ( $\mathrm{p}<0.001$ ).

Conclusions: We found medical management definitely improved quality of life in BPH patients and significantly decreased symptoms. This study is a step in the direction of development of larger and longer term PRO studies in BPH management.
\end{abstract}

Keywords: Benign prostatic hyperplasia, $\mathrm{BPH}$ impact index, Health related quality of life, International prostate symptom score, Lower urinary tract symptoms, Patient reported outcome

\section{INTRODUCTION}

Benign prostatic hyperplasia (BPH) is a common condition affecting middle aged and elderly men. Though $\mathrm{BPH}$ is not life threatening, its clinical manifestations affect the quality of life of the patients considerably. The symptoms of BPH include increased urinary frequency, urgency, hesitancy, slow stream, nocturia. The enlarged gland contributes to the lower urinary tract symptoms (LUTS). With time, these symptoms of incomplete emptying may lead to chronic bladder over-distension. 
This leads to defunctionalized bladder, which may go on to become irreversible with time. ${ }^{1}$

Although LUTS secondary to BPH (LUTS/BPH) is not often a life-threatening condition, the impact of LUTS on quality of life (QoL) is significant. The most important reasons for seeking treatment include the severity and the degree of bother associated with the symptoms. These are also important considerations when assessing the effectiveness of treatment of BPH and deciding when and what treatment is indicated. The severity of bothering symptoms is assessed by International Prostate Symptom Score (I-PSS), BPH Impact Index (BII). ${ }^{1}$

Traditionally, the main goal of medical management of $\mathrm{BPH}$ is to alleviate LUTS that result from prostatic enlargement. More recently, treatment also focuses on the alteration of disease progression and prevention of complications that can be associated with BPH/LUTS. A variety of different groups of drugs are employed in treating BPH including alpha-adrenergic antagonists (alpha-blockers), 5-alpha reductase inhibitors (5-ARIs), anticholinergics etc. ${ }^{1}$ Choosing the correct medical treatment for BPH is often a complicated process and must meet the demands of patient satisfaction for long term compliance.

Patient Reported Outcomes (PRO) studies measure aspects of patient's health status that is reported directly from the patient without any influence from a physician or outside agent. ${ }^{2}$ PROs can be used to measure the impact of a treatment on one or more aspects of patients' well being, covering various aspects such as symptomatic as well as other areas such as quality of life. As there is no available data regarding PROs in BPH treatment in India, so this study aimed at filling this gap and gather relevant information. We also attempted to understand the pattern of drug use in BPH patients in our set up.

\section{METHODS}

The study was designed as a prospective, observational study. Male patients, aged between 40 to 80 years, attending the out-patient department (OPD) of Urology, at a tertiary care teaching hospital in rural West Bengal, and diagnosed as BPH, were screened and recruited in the study after satisfying the inclusion and exclusion criteria and following satisfactory completion of informed consent process.

The target sample size was around 60. Considering $20 \%$ drop-out rate, the number of patients required to be recruited was found to be 70 to 80 . The primary objective of this study was to assess the outcomes and impact on quality of life by medical management of BPH patients. Inclusion criteria included newly registered and newly diagnosed patients presented with symptoms of BPH in the age group of 40 to 80 years, who have attended Urology OPD between March 2014 and October 2014. Exclusion criteria included non-consent, indications for or preference for surgical treatment. Further patients who received pharmacotherapy for $\mathrm{BPH}$ more than 2 weeks were excluded as were other seriously ill, diabetic or catheterized patients.

Patients were thoroughly checked and treated by the Urologist. Laboratory investigations prescribed included routine blood tests including blood sugar, USG, Uroflowmetry, Prostate Specific Antigen (PSA).

Patients were interviewed with the predefined questionnaires- I-PSS, BPH Impact Index (BII), HRQOL Scoring System and respective scores noted along with the clinical and laboratory findings. The patients were asked to report immediately over telephone if any medical emergency or any untoward reactions occurred.

After three and six months of baseline visit, the patient was re-assessed for response to medical management in terms of I-PSS, BPH Impact Index (BII), HRQOL Scoring System. General examination finding and laboratory investigations reports after three and six months of treatments were noted.

\section{International prostate symptom score (I-PSS)}

The International Prostate Symptom Score (I-PSS) is based on the answers to seven questions concerning urinary symptoms and one question concerning quality of life. Each question regarding the urinary symptoms are set so that the patient chooses one out of six answers indicating severity of the symptom in question. The answers are assigned points from 0 to 5 . The total score can range from 0 to 35 (asymptomatic to very symptomatic). ${ }^{1,3}$

The first seven questions of the I-PSS are same as the questions appearing on the American Urological Association (AUA) Symptom Index which categorizes symptoms as mild (symptom score less than equal to 7), moderate (symptom score 8-19), severe (symptom score 20-35). The International Scientific Committee (SCI), under the World Health Organization (WHO) and the International Union Against Cancer (UICC), recommends the use of a single question to assess the quality of life. The answers to this question lies within the range of "delighted" to "terrible" or 0 to $6 .{ }^{1}$

\section{BPH Impact index}

This is used to assess the significance and current status of the BPH impact index (BII) in the evaluation of subjective symptoms of difficult urination. Total scoring is based on 0-4 point scale..$^{1,4,5}$

\section{EQ-5D-5L (quality of life assessment)}

EQ-5D is a measure of health status developed by the EuroQol Group to provide a simple measure of health and well being for clinical evaluation. The EQ-5D-5L 
consists of the EQ-5D-5L descriptive system and the EQ Visual Analogue scale (EQ VAS). The descriptive system has of 5 components and each component has 5 levels. The EQ VAS records the respondent's self-rated health on a $20 \mathrm{~cm}$ vertical, visual analogue scale..$^{6-9}$

\section{Statistical analysis}

Data were entered in Microsoft Excel 2007 and analysis was done with the help of SPSS version 22 and Epi Calc 2000. Continuous variables were compared by paired $t$ test. Categorical data were compared by chi-square test. A $\mathrm{p}$ value of less than 0.05 was considered statistically significant.

\section{RESULTS}

Between March and October 2014, out of a total number of 165 patients of BPH attending the OPD, 85 patients with symptomatic BPH but not having an absolute indication for surgery, between the age group of 40-80 years of age, were included in our study. Of these 19 patients were lost to follow-up and 66 patients were analyzed for different parameters.

All the study subjects were recruited in the out-patient department. The average age of the patients was $59.83 \pm 10.15$ years. Table 1 summarizes the vital signs and laboratory parameters recorded at baseline, 1st follow-up and at 2 nd follow-up visit. The changes were not statistically significant.

Table 1: Baseline and follow up clinical and laboratory parameters of the participants.

\begin{tabular}{|c|c|c|c|}
\hline Category & $\begin{array}{l}\text { Baseline } \\
(\text { Mean } \pm \text { SD) }\end{array}$ & $\begin{array}{l}1^{\text {st }} \text { Follow- } \\
\text { up } \\
(\text { Mean } \pm S D)\end{array}$ & $\begin{array}{l}2^{\text {nd }} \text { Follow- } \\
\text { up } \\
(\text { Mean } \pm \text { SD })\end{array}$ \\
\hline $\begin{array}{l}\text { Pulse } \\
\text { (beats/min) }\end{array}$ & $67.59 \pm 5.02$ & $65.27 \pm 4.85$ & $66.03 \pm 4.86$ \\
\hline $\begin{array}{l}\text { SBP } \\
(\mathrm{mm} \text { hg) }\end{array}$ & $132.94 \pm 10.34$ & $130.06 \pm 8.06$ & $128.33 \pm 7.50$ \\
\hline $\begin{array}{l}\text { DBP } \\
(\mathrm{mm} \mathrm{hg})\end{array}$ & $78.27 \pm 11.35$ & $75.74 \pm 10.80$ & $74.80 \pm 10.50$ \\
\hline $\begin{array}{l}\text { Creatinine } \\
(\mathrm{mg} / \mathrm{dl})\end{array}$ & $0.98 \pm 0.26$ & $1.01 \pm 0.25$ & $1.02 \pm 0.22$ \\
\hline $\begin{array}{l}\text { Urea } \\
(\mathrm{mg} / \mathrm{dl})\end{array}$ & $30.09 \pm 5.70$ & $30.97 \pm 4.99$ & $31.15 \pm 4.22$ \\
\hline $\begin{array}{l}\text { PSA } \\
(\mathrm{ng} / \mathrm{ml})\end{array}$ & $0.44 \pm 0.45$ & $0.47 \pm 0.46$ & $0.47 \pm 0.37$ \\
\hline $\begin{array}{l}\text { FBS } \\
(\mathrm{mg} / \mathrm{dl})\end{array}$ & $87.15 \pm 11.64$ & $91.09 \pm 9.55$ & $94.54 \pm 11.07$ \\
\hline $\begin{array}{l}\text { PPBS } \\
(\mathrm{mg} / \mathrm{dl})\end{array}$ & $120.66 \pm 10.08$ & $121.42 \pm 9.68$ & $126.71 \pm 9.63$ \\
\hline
\end{tabular}

SD = Standard Deviation, SBP = Systolic Blood Pressure, DBP $=$ Diastolic Blood Pressure, FBS= Fasting Blood Sugar, PPBS= Postprandial Blood Sugar

As medical management of $\mathrm{BPH}, 5 \alpha$-reductase inhibitors and $\alpha$ adrenergic blockers were used. Finasteride and dutasteride were the $5 \alpha$-reductase inhibitors used. Tamsulosin and Silodosin were the two $\alpha$ adrenergic blockers used in medical management. As a monotherapy, only $\alpha$ adrenergic blockers were used. In this study $33(50 \%)$ patients were treated by mono-therapy and rest of study subjects $(50 \%)$ were treated by combination therapy. Figure 1 shows the drug usage pattern among the study subjects.

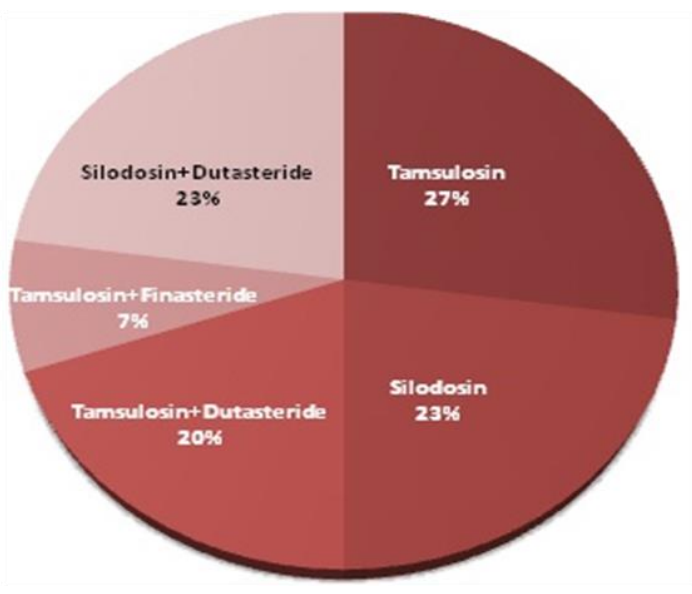

Figure 1: Trends of drug use in BPH management in our study.

There was a significant decrease in the each parameter of IPSS scores and IPSS total score decreased significantly, at the first and second follow-up. These changes observed were also reflected in IPSS 8Q score, at the ends of third months and sixth months of treatment. The results are evident in Table 2.

Table 2: Changes in International Prostate Symptom Score (I-PSS) and IPSS-8Q score.

\begin{tabular}{|lll|l|}
\hline Parameter & $\begin{array}{l}\text { Baseline } \\
\text { (Mean } \pm \text { SD })\end{array}$ & $\begin{array}{l}\mathbf{1}^{\text {st }} \text { Follow- } \\
\text { up } \\
(\text { Mean } \pm \text { SD })\end{array}$ & $\begin{array}{l}2^{\text {nd }} \text { Follow- } \\
\text { up } \\
(\text { Mean } \pm \text { SD })\end{array}$ \\
\hline $\begin{array}{l}\text { Incomplete } \\
\text { Emptying }\end{array}$ & $2.82 \pm 0.98$ & $2.18 \pm 0.86^{*}$ & $1.82 \pm 0.74^{*}$ \\
\hline Frequency & $3.02 \pm 1.02$ & $2.24 \pm 0.93^{*}$ & $1.80 \pm 0.68^{*}$ \\
\hline Intermittency & $2.67 \pm 1.09$ & $2.02 \pm 0.92^{*}$ & $1.71 \pm 0.74^{*}$ \\
\hline Urgency & $2.52 \pm 1.19$ & $1.80 \pm 1.00^{*}$ & $1.45 \pm .81^{*}$ \\
\hline Weak stream & $2.27 \pm .92$ & $1.74 \pm 0.77^{*}$ & $1.62 \pm 0.74^{*}$ \\
\hline Straining & $2.26 \pm 1.00$ & $1.65 \pm .71^{*}$ & $1.47 \pm .59^{*}$ \\
\hline Nocturia & $3.32 \pm 1.43$ & $2.50 \pm 1.15^{*}$ & $1.86 \pm .89^{*}$ \\
\hline $\begin{array}{l}\text { Total I-PSS } \\
\text { score }\end{array}$ & $18.86 \pm 5.53$ & $14.14 \pm 4.78^{*}$ & $11.76 \pm 3.94^{*}$ \\
\hline $\begin{array}{l}\text { I-PSS 8Q } \\
\text { score }\end{array}$ & $3.79 \pm 1.07$ & $3.36 \pm 1.08^{*}$ & $2.77 \pm 1.12^{*}$ \\
\hline
\end{tabular}

Paired $\mathrm{t}$ test used to compare with baseline; $* \mathrm{p} \leq 0.001$

There was significant decrease in BPH Impact Index in first and second follow-up. There was significant improvement after six months treatments on assessment with VAS score. Both results are depicted in Table 3. 
Table 3: Changes in BPH Impact Index (BII) and Visual Analogue Scale (VAS) scores.

\begin{tabular}{|llll|}
\hline & $\begin{array}{l}\text { Baseline } \\
(\text { Mean } \pm \text { SD })\end{array}$ & $\begin{array}{l}1^{\text {st }} \text { Follow-up } \\
(\text { Mean } \pm \text { SD })\end{array}$ & $\begin{array}{l}2^{\text {nd }} \text { Follow-up } \\
(\text { Mean } \pm \text { SD })\end{array}$ \\
\hline $\begin{array}{l}\text { BII } \\
\text { Score }\end{array}$ & $9.65 \pm 2.59$ & $6.83 \pm 2.29 *$ & $5.89 \pm 2.24^{*}$ \\
\hline $\begin{array}{l}\text { VAS } \\
\text { Score }\end{array}$ & $49.02 \pm 9.37$ & $51.44 \pm 10.03 *$ & $54.24 \pm 11.38^{*}$ \\
\hline
\end{tabular}

Paired t test used to compare with baseline; $* \mathrm{p} \leq 0.001$

Changes in HRQOL (EQ-5D-5L) showed that treatment had no statistically significant effect on mobility, self care and usual activities. However, statistically and clinically significant improvements were seen in terms of alleviation of pain and discomfort and anxiety and depression. Chi square tests were used for comparison. The results are depicted in Figure 2 (A to E).

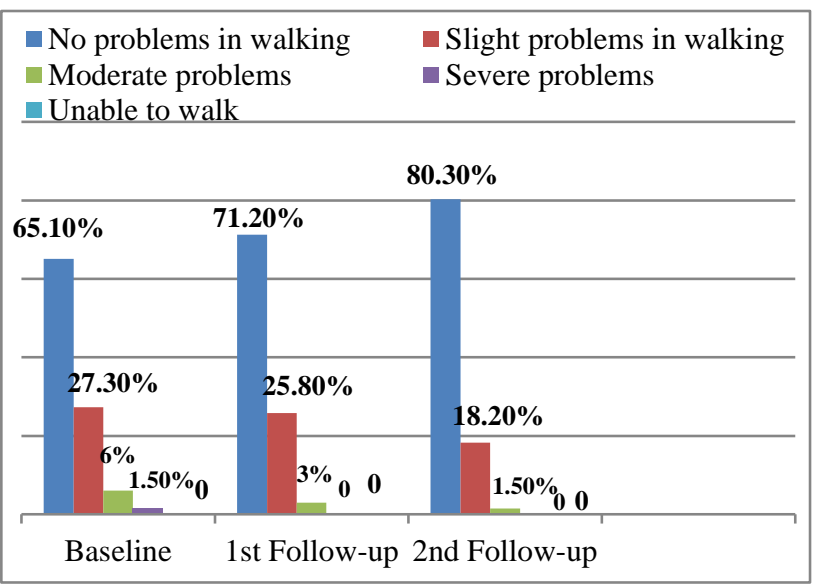

Figure 2 (A): Changes in mobility.

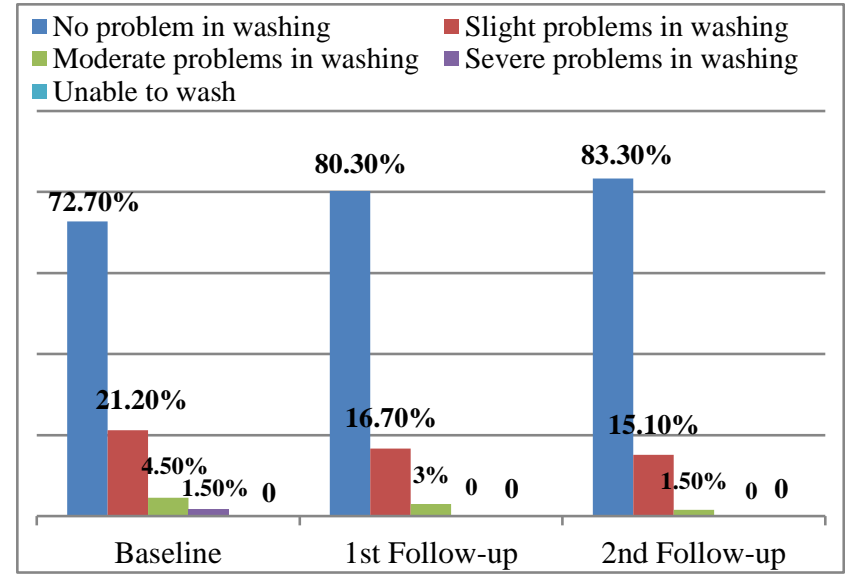

Figure 2 (B): Changes in self-care.

There was significant improvement of maximum flow rate $(11.71 \pm 3.35$ at baseline to $14.72 \pm 3.64$ at 6 months; $p$ $<0.001)$ and average flow rate $(2.63 \pm 1.18$ at baseline to $3.61 \pm 1.24$ at 6 months; $\mathrm{p}<0.001)$ of urine flow and also significantly decreased prostate size $(32.69 \pm 14.73$ at baseline to $27.98 \pm 11.02$ at 6 months; $p<0.001)$ and post residual urine volume $(131.30 \pm 136.86$ at baseline to $61.29 \pm 47.25$ at 6 months; $p<0.001)$ after six months of medical treatment.

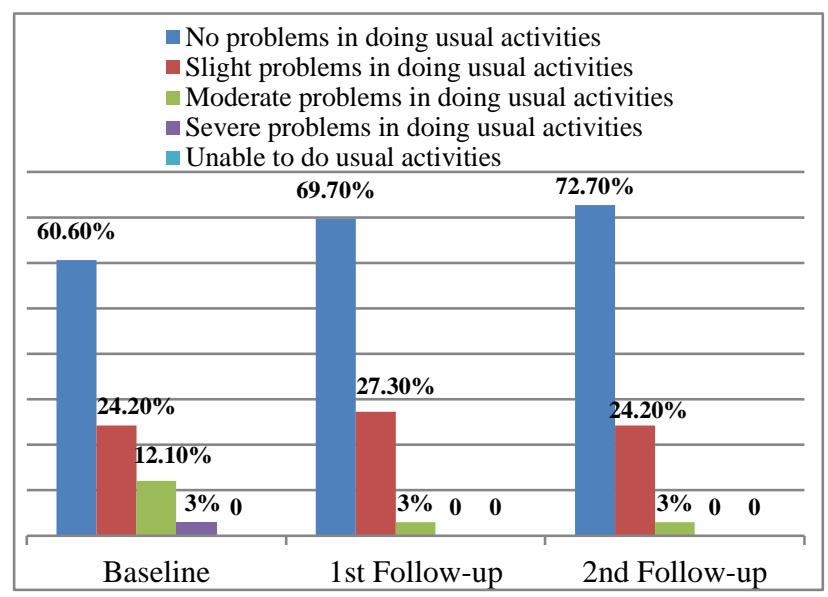

Figure 2 (C): Changes in usual activities.

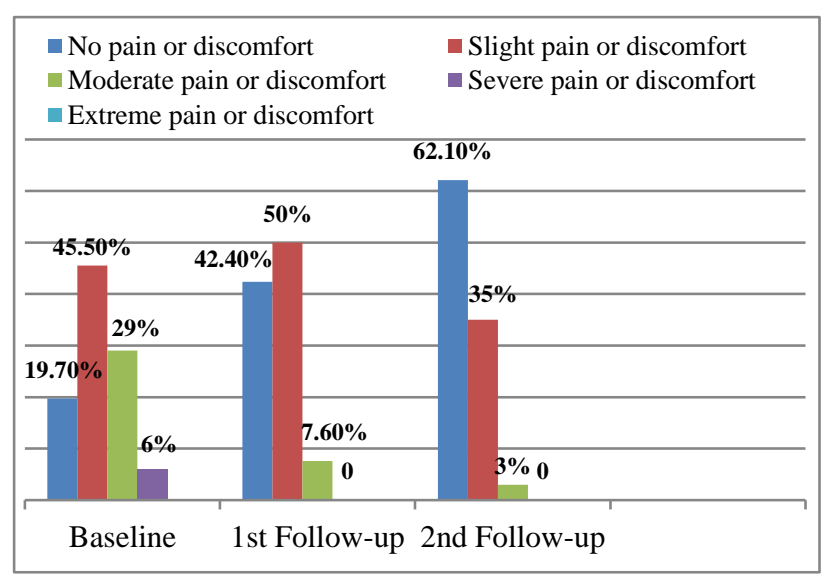

Figure 2 (D): Changes in pain or discomfort.

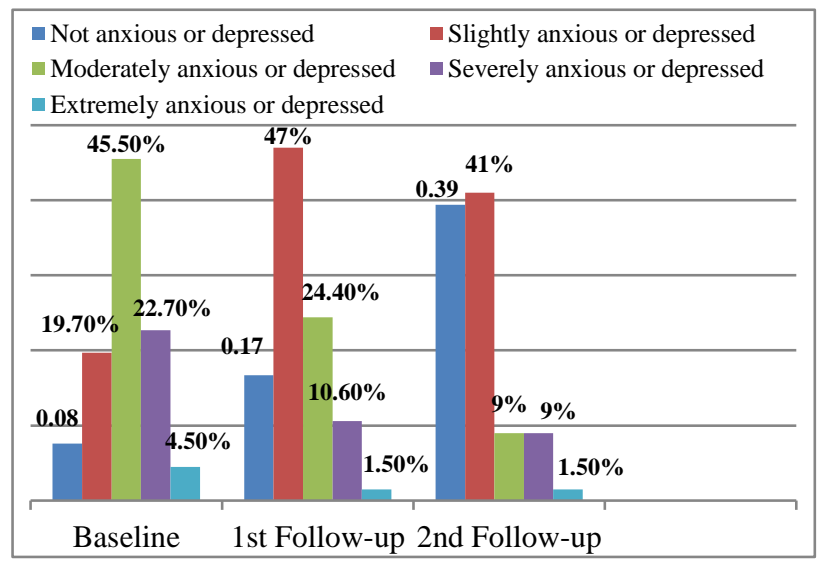

Figure 2 (E): Changes in anxiety/depression score.

Figure 2: Changes in HRQOL (EQ-5D-5L) measured for each 5 parameters $(* p \leq 0.001) ; 2$ (A): Changes in mobility; 2 (B): Changes in self care; 2 (C): Changes is usual activities; 2 (D): Changes in pain or discomfort; 2 (E): Changes in anxiety/depression scores. 
There were no significant adverse reactions that were observed during our study period. One patient complained of loss of libido and two patients reported with postural hypotension, headache and dizziness. No serious adverse drug reactions were reported during our study period.

\section{DISCUSSION}

Symptomatic BPH occurs in almost $90 \%$ of men in between the ages of 40 and 80 years. Nearly all men develop microscopic BPH by the age of 90 years. It is also described as quality of life disorder, affecting man's ability to initiate or terminate urine flow stream. Since these symptoms interfere with the normal activities, they reduce the feeling of well being. ${ }^{3,10}$

Patient Reported Outcomes (PRO) studies measure aspects of patient's health status that is reported by the patient with no influence from a physician. PROs can be used to measure the impact of a treatment on various aspects of patients' health and well being, ranging from symptomatic to concepts such as quality of life. ${ }^{2}$

This study was designed as a prospective, observational study. In this PRO study population of 66 patients, 50\% were treated with monotherapy (alpha blocker) and 50\% were treated with combinations (alpha blocker +5 alpha reductase inhibitor). After 6 months of medical management, both I-PSS and BII scores were significantly decreased. On second follow-up, VAS score also increased significantly.

HRQoL is an important measure in treatment assessment of many diseases that affect the feeling of well being. There are no clear guidelines or studies for understanding the relationship between HRQoL and PROs. There are several sources of data to assess the safety and efficacy of a new drug that not only include clinicians but also patients and caregivers. Each of these sources can provide a unique and valuable perspective on both the disease as well as the efficacy of a therapy. While patients may focus on the changes in their own health, caregivers and family may focus not only on the patient but also on the impact on family life. On part of the clinician and researchers, the disease and its treatment is viewed from a clinical perspective. HRQoL is one of several types of PRO data that may be collected from a clinical trial. Other PROs include handling of symptoms, patient satisfaction with treatment, functional status, psychological health, and treatment compliance. Patient's evaluation implies that the patient is the preferred respondent in the study. ${ }^{2}$

There are no PROs in this disease setting. However quite a few quality of life studies have been done with medical management of BPH. Suzuki et al for example, described the efficiency of $\alpha 1$-blocker treatment on disease-specific and generic quality of life in men with clinically diagnosed BPH, the improvement of QoL scores with I-
PSS. All questionnaires in the I-PSS showed improvement after tamsulosin treatment. ${ }^{11}$ Desgrandchamps et al evaluated the efficacy and safety in clinical practice of dutasteride and the I-PSS decreased from baseline. There were significant $(\mathrm{P}<0.001)$ decreases in all the individual I-PSS items at 12 and 24 weeks, with more marked improvements in voiding symptoms than storage symptoms. There were also significant $(\mathrm{P}<0.001)$ improvements in the BII and VAS scores for patient discomfort and satisfaction at both times. $^{12}$

Wilt et al reviewed 14 studies involving 4,122 subjects, with mean age of subjects being 64 years. Tamsulosin improved symptoms and peak urine flow rates relative to placebo. ${ }^{13}$ Wilt et al reviewed 17 studies involving 5,151 subjects, evaluated alpha-blockers, finasteride alone or in combination with terazosin as well as placebo microwave therapy (TUMT). Terazosin improved symptom scores and flow rates more than placebo or finasteride and similarly to other alpha antagonists. The pooled mean improvement in the I-PSS was similar to tamsulosin. Peak urine flow rates improved greater with terazosin, than placebo and finasteride but did not differ significantly from the other alpha-blockers. The discontinuation rates of terazosin were comparable to men receiving placebo and finasteride but was greater than with other alpha-antagonists. ${ }^{14}$

The Roehrborn et al report demonstrated that longer-term treatment over 48 months with dutasteride results in improvements in urinary symptoms and flow rate, and reductions in total and transition zone volume of the prostate in men with symptomatic BPH. The reduction in risk of acute urinary retention and BPH-related surgery after dutasteride therapy was also noted. ${ }^{15}$ Debruyne et al, observed that significant improvements in AUA-SI score and $\mathrm{Q}(\max )$ in study groups on Dutasteride. ${ }^{16} \mathrm{O}$ 'leary et al, described a study where dutasteride use resulted in clinically and statistically significant improvements in mean BII score from 6 months. ${ }^{17}$ In our study dutasteride was only given as combination therapy.

Osman et al, in their study, demonstrated long-term treatment with silodosin was safe and efficacious. A total of 500 patients entered the 9-month open-label study. Adverse events were experienced by $33.4 \%$ patients. Ejaculation dysfunction was the most common TEAE $(9.0 \%)$ and led to discontinuation of the study by $1.6 \%$ of patients. Dizziness but not orthostatic hypotension occurred in $0.8 \%$. A significant reduction in total IPSS ($2.7 \pm 3.8$ ) was documented at the first visit of this extension phase in patients having silodosin compared with lesser improvement in patients previously treated with silodosin $(-0.82 \pm 4.2)$ or tamsulosin $(-0.83 \pm 3.8)$. QoL improved, with the greatest improvement in silodosin patients. ${ }^{18}$ Although American Urological Association Guideline for management of BPH does not recommend long term use of silodosin, Osman et al study supports the long term use of silodosin in BPH without any significant 
complications. ${ }^{1}$ This is also supported in our study results regarding long term use of silodosin.

Roehrborn et al study showed that combination therapy was significantly superior to tamsulosin monotherapy but not dutasteride monotherapy in reducing the relative risk of acute urinary retention or BPH-related surgery. Combination therapy was also found to be superior to both monotherapies at reducing the relative risk of BPH progression. Combination therapy provided significantly better symptoms benefit than either monotherapy at 4 years. ${ }^{19}$ This study supported the use of combination therapy instead of monotherapy. In our study results showed that $50 \%$ patients were prescribed combination therapy and dutasteride was not used as a monotherapy.

The present study had certain limitations. Firstly, the sample size was calculated on the basis of presentation of patients on Urology OPD and a large sample may have shown a clearer statistical significance in the results. Secondly, the study was observational due to lack of resources required for a Phase IV clinical trial. Thus the prescription pattern was studied rather than a fixed number of patients receiving particular therapies in different groups. In addition, we also noted an increased use of Silodosin that is not seen in any other study or is recommended in the guidelines. Silodosin has been used alone or in combination in a large proportion of our study patients. Thirdly, the treatment period in this study was relatively short and hence it provided less scope for assessing effectiveness of long-term therapy as BPH is chronic disease. Finally, we assessed PRO in medical management alone and further studies comparing medical and surgical management are needed as surgical management is the gold standard for management of $\mathrm{BPH}$.

\section{CONCLUSION}

Medical management significantly decreased the symptoms of BPH and also improved quality of life in BPH patients. This study however is a step in the direction of development of larger and longer term PRO studies in BPH management.

Funding: No funding sources

Conflict of interest: None declared

Ethical approval: The study was approved by the Institutional Ethics Committee

\section{REFERENCES}

1. American Urological Association. American Urological Association Guideline: Management of Benign Prostatic Hyperplasia (BPH) Revised. 2010. Available from: https://www.auanet.org/education/guidelines/benignprostatic-hyperplasia.cfm. Accessed on 11th July 2016.
2. Acquadro C, Berzon R, Dubois D, Leidy NL, Marquis P, Revicki D et al. Incorporating the Patient's Perspective into Drug Development and Communication: An Ad Hoc Task Force Report of the Patient-Reported Outcomes (PRO) Harmonization Group Meeting at the Food and Drug Administration, February 16, 2001. Value Health 2003;6:522-31.

3. Roehrborn CG. Benign prostatic hyperplasia: Etiology, pathophysiology, epidemiology, and natural history. In: Campbell-Walsh Urology. 10 ${ }^{\text {th }}$ Edition. Philadelphia. Elsevier; 2012:2570-2608.

4. Madersbacher S, Alivizatos G, Nordling J, Sanz CR, Emberton M, de la Rosette JJ. EAU 2004 guidelines on assessment, therapy and follow-up of men with lower urinary tract symptoms suggestive of benign prostatic obstruction (BPH guidelines). Euro $\mathrm{J}$ of Uro. 2004;46:547-54.

5. Ikemoto I, Kiyota H, Suzuki Y, Oishi Y, Kishimoto $\mathrm{K}$, Shimomura T, et al. Roles of BPH impact index in the evaluation of impaired urination in patients with BPH. The Japanese Journal of Urology. 2005;96:62331.

6. Chevalier J, De Pourville G. Valuing EQ-5D using time trade-off in France. European Journal of Health Economics. 2013;14:57-66.

7. Fourcade RO, Lacoin F, Roupret M, Slama A, Fur CL, Michel E et al. Outcomes and general healthrelated quality of life among patients medically treated in general daily practice for lower urinary tract symptoms due to benign prostatic hyperplasia. World J of Uro. 2012;30:419-26.

8. Herdman M, Gudex C, Lloyd A, Janssen MF, Kind $\mathrm{P}$, Parkin D, et al. Development and preliminary testing of the new five-level version of EQ-5D (EQ5D-5L). Quality of Life Research. 2011;20:1727-36.

9. Devlin NJ, Krabbe PFM. The development of new research methods for the valuation of EQ-5D-5L. European Journal of Health Economics. 2013;14(1):S1-3.

10. Dhingra N, Bhagwat D. Benign prostatic hyperplasia: An overview of existing treatment. Ind $\mathbf{J}$ of Pha. 2011;43:6-12.

11. Suzuki H, Yano M, Yusuke A, Nakatsu H, Egoshi KI, Mikami K et al. Clinical impact of tamsulosin on generic and symptom-specific quality of life for benign prostatic hyperplasia patients: Using international prostate symptom score and Rand Medical Outcomes Study 36-item Health Survey. Int J of Uro. 2006;13:1202-6.

12. Desgrandchamps F, Droupy S, Irani J, Saussine C, Comenducci A. Effect of dutasteride on the symptoms of benign prostatic hyperplasia, and patient quality of life and discomfort, in clinical practice. BJU International. 2006;98:83-8.

13. Wilt T, MacDonald R, Rutks I. Tamsulosin for benign prostatic hyperplasia (Review). Cochrane Database Syst Rev. 2003;1:CD002081. 
14. Wilt T, Howe RW, Rutks I, MacDonald R. Terazosin for benign prostatic hyperplasia (Review). Cochrane Database Syst Rev. 2002;4:CD003851.

15. Roehrborn CG. The clinical benefits of dutasteride treatment for LUTS and BPH. Reviews in Urology. 2004;6:S22-30.

16. Debruyne F, Barkin J, Van Erps P, Reis M, Tammela TL, Roehrborn CG et al. Efficacy and safety of longterm treatment with the dual 5 alpha-reductase inhibitor dutasteride in men with symptomatic benign prostatic hyperplasia. European Urology. 2004;46:488-95.

17. O'leary MP, Roehrborn CG, Andriole G, Nickel C, Boyle P, Höfner K. Improvements in benign prostatic hyperplasia-specific quality of life with dutasteride, the novel dual $5 \alpha$ - reductase inhibitor. BJU International. 2003;92:262-6.

18. Osman N, Chapple CR, Tamela TL, Eisenhardt A, Oelke M. Open-label, 9-month extension study investigating the uro-selective alpha-blocker silodosin in men with LUTS associated with BPH. World J of Uro. 2015;33:697-706.

19. Roehrborn CG, Siami P, Barkin J, Damião R, Walker MK, Nandy I et al. The effects of combination therapy with dutasteride and tamsulosin on clinical outcomes in men with symptomatic benign prostatic hyperplasia: 4-year results from the Comb AT study. European Urology. 2010;57:123-31.

Cite this article as: Mandal S, Mandal A, Majhi TK, Mandal S, Gangopadhyay T, Das AK. Patientreported outcomes with medical management of benign prostatic hyperplasia: a prospective study in a tertiary care teaching hospital of rural West Bengal, India. Int J Basic Clin Pharmacol 2017;6:1631-7. 